\title{
ON THE ORIGIN AND IMPACT OF MESENCHYMAL STEM CELL HETEROGENEITY: NEW INSIGHTS AND EMERGING TOOLS FOR SINGLE CELL ANALYSIS
}

\author{
C.M. McLeod ${ }^{1,2,3}$ and R.L. Mauck ${ }^{1,2,3 *}$ \\ ${ }^{1}$ Department of Bioengineering, University of Pennsylvania, Philadelphia, PA 19104, USA \\ ${ }^{2}$ McKay Orthopaedic Research Laboratory, Department of Orthopaedic Surgery, \\ Perelman School of Medicine, University of Pennsylvania, Philadelphia, PA 19104, USA \\ ${ }^{3}$ Translational Musculoskeletal Research Center, Philadelphia VA Medical Center, Philadelphia, \\ PA 19104, USA.
}

\begin{abstract}
Mesenchymal stem cells (MSCs) display substantial cell-to-cell variation. This heterogeneity manifests among donors, among tissue sources, and within cell populations. Such pervasive variability complicates the use of MSCs in regenerative applications and may limit their therapeutic efficacy. Most conventional assays measure MSC properties in bulk and, as a consequence, mask this cell-to-cell variation. Recent studies have identified extensive variability amongst and within clonal MSC populations, in dimensions including functional differentiation capacity, molecular state (e.g. epigenetic, transcriptomic, and proteomic status), and biophysical properties. While the origins of these variations remain to be elucidated, potential mechanisms include in vivo micro-anatomical heterogeneity, epigenetic bistability, and transcriptional fluctuations. Emerging tools for single cell analysis of MSC gene and protein expression may yield further insight into the mechanisms and implications of single cell variation amongst these cells, and ultimately improve the clinical utility of MSCs in tissue engineering and regenerative medicine applications. This review outlines the dimensions across which MSC heterogeneity is present, defines some of the known mechanisms that govern this heterogeneity, and highlights emerging technologies that may further refine our understanding and improve our clinical application of this unique cell type.
\end{abstract}

Key words: Stem cells - differentiation, tissue engineering/regenerative medicine, cells/tissue - analytical methods, genetics - gene expression, proteomics.

*Address for correspondence: Robert L. Mauck, PhD, McKay Orthopaedic Research Laboratory, University of Pennsylvania, 424 Stemmler Hall, $36^{\text {th }}$ Street and Hamilton Walk, Philadelphia, PA 19104, USA

Telephone: 1-215-898-3294ＦAX: 1-215-573-2133Ｅ-mail: lemauck@pennmedicine.upenn.edu

\section{Introduction}

In tissue engineering applications, the structure and function of the extracellular matrix (ECM) are crucial determinants of the success or failure of an engineered construct. The ECM is created and maintained by resident cells, and hence, the choice of cell source strongly influences construct performance. For example, in engineered cartilage, the quality and organisation of the matrix produced differs substantially based on the cell types employed. Chondrocytes, the cells resident in native cartilage, excel at producing robust extracellular matrices in vitro, even under nutrient limiting conditions (Johnstone et al., 2013; Kock et al., 2012). Unfortunately, chondrocytes are difficult to obtain in sufficient number, and chondrogenically induced stem cells are often used as an alternative. Mesenchymal stem cells (MSCs) are readily obtained from adult tissue, expand well in culture, and can undergo chondrogenic differentiation. However, even with the most effective differentiation protocols, MSCs generally fail to fully match the performance of chondrocytes (Huang et al., 2010; Johnstone et al., 2013). Such gaps in performance between MSCs and differentiated cell types likely exist, in part, as a consequence of marked variation in the ability of individual MSCs to undergo lineage commitment. Some MSCs robustly undergo differentiation while others fail to do so (Huang et al., 2010). While these underperforming, alternatively performing or nonresponsive subpopulations hinder the maturation of engineered tissues, their poor performance is often masked by bulk assays that pool signal across entire cell populations (Fig. 1). Recently, given the advent of single cell methods and a growing 
appreciation that ensemble measurements can mask important variation, new findings have begun to delineate MSC heterogeneity. Here, we review the current understanding of heterogeneity among and within MSC populations, and discuss how single cell techniques may be used to further parse this variability.

\section{Mesenchymal stem cell heterogeneity}

The defining properties of mesenchymal stem cells

As a cell type, MSCs are defined by three criteria. MSCs must: 1) be plastic adherent; 2) express the surface markers CD105, CD73 and CD90, and lack expression of CD45, CD14 or CD11b, CD79 or CD19 and HLA-DR; and 3) be capable of differentiating into osteoblasts, adipocytes, and chondroblasts (Bourin et al., 2013; Dominici et al., 2006). These criteria are periodically updated, and the reader is referred to the website of the International Society for Cellular Therapy MSC Subcommittee for the most up-to-date information (Web ref.1). Even so, this operational definition does not necessarily define a homogenous population of multipotent progenitors. Instead, it describes a heterogeneous group of cells that demonstrate variability among tissues of origin, among individual donors, amongst clonal subpopulations, and at the single cell level (Fig. 2).

MSCs exhibit heterogeneity on multiple levels While MSCs were first isolated from bone marrow (Friedenstein, 1976; Johnstone et al., 1998; Pittenger et al., 1999), they have since been identified in many connective tissues, including adipose tissue, the
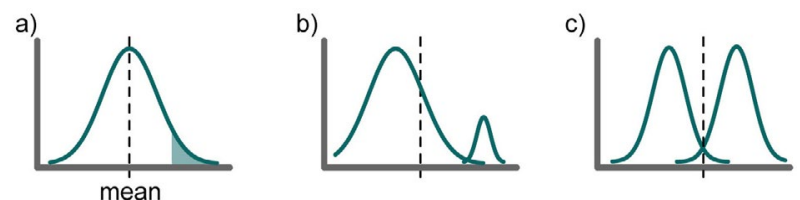

Fig. 1. Bulk observations can mask heterogeneity, including a) 'tail' observations, b) small subpopulations, and c) bimodal behaviour. Inspired by Altschuler and Wu, 2010.

umbilical cord and dental pulp (Erices et al., 2000; Gronthos et al., 2000; Zuk et al., 2001) to name a few. In standard isolation techniques, adipose or bone marrow aspirates are progressively centrifuged, and filtered before being plated into culture. A small fraction of the cells (the presumed MSCs) will adhere to the tissue culture plastic, and proliferate. Both bone marrow- and adipose-derived MSCs are readily available (Estes et al., 2010), yet they originate from stem cell niches that provide distinct biological, chemical and mechanical cues. Tissue-dependent variation in differentiation capacity, surface markers and transcriptional and proteomic profiles is widely studied, and the reader is referred to recent reviews for comparisons of MSCs across tissue sources (Kern et al., 2006; Mattar and Bieback, 2015; Strioga et al., 2012).

Even when derived from the same tissue of origin, MSCs demonstrate tremendous donor-to-donor variability. Intuitively, donor health may influence the availability and functional potential of MSCs (Kuznetsov et al., 2009; Wang et al., 2013). Similarly, as donors age, MSC availability, self-renewal capacity

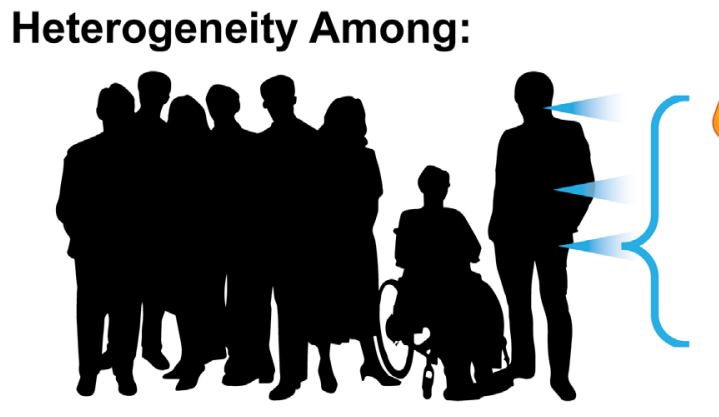

Donors

Phinney et al., 1999

D'Ippolito et al., 1999

Kuznetsov et al., 2009

Mindaye et al., 2013

$\vdots$
Tissues

Johnstone et al., 1998

Pittenger et al., 1999

Erices et al., 2000

Gronthos et al., 2000

Zuk et al., 2001

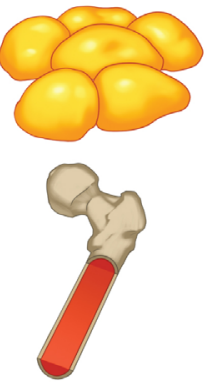

Clones

Muraglia et al., 2000

Larsen et al., 2010

Russell et al., 2011

González-Cruz et al., 2012

Selich et al., 2016

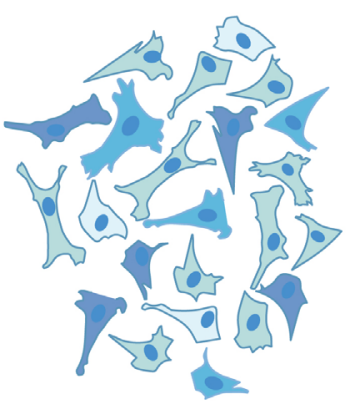

Single Cells

Lee et al., 2014

Marble et al., 2014

Freeman et al., 2015

Cote et al., 2016

Li et al., 2016

$$
\vdots
$$

Fig. 2. MSC heterogeneity exists at multiple levels, including among donors, tissues, clonal subpopulations, and single cells. Selected works are highlighted at each of these levels. 
and differentiation potential have been reported to decline (D'Ippolito et al., 1999; Katsara et al., 2011; Stenderup et al., 2003). Surprisingly, however, even MSCs isolated from young, healthy donors exhibit stark differences in their proliferation rate, differentiation capacity, and ultimate clinical utility (Phinney et al., 1999). This functional variation extends to the molecular status of these cells (Mindaye et al., 2013; Mindaye et al., 2015). For example, mass spectroscopy of MSCs isolated from six donors revealed that only $62 \%$ of all identified proteins were found in at least half of the donors, and only $13 \%$ of identified proteins were found in cells from each donor (Mindaye et al., 2013). Such donorto-donor variation complicates use, and motivates a more detailed investigation of MSC variability.

Further study revealed that donor- and tissuedependent differences are superimposed upon cell-to-cell variation amongst MSCs within a single population. For example, multiple bone marrow aspirates isolated from the same donor over a period of six months, or bilaterally from a donor at a single time point, yield MSC cultures that proliferate at different rates (Phinney et al., 1999). Even within a single isolate, cell-to-cell variation in MSC phenotype becomes evident during culture expansion and downstream use (Fig. 3, Fig. 4). This variation is commonly examined by comparing clonal subpopulations (groups of cells that are not only genetically identical, but also recently derived from single parent cells) (Huang, 2009).

MSCs readily form clones, and their clonogenicity can be observed by sparsely plating an initial isolate and monitoring colony formation. Clonal subpopulations can be obtained by sub-culturing these colonies, or by seeding single cells into individual culture wells by limiting dilution or flow cytometry (Smith et al., 2004). While variability is
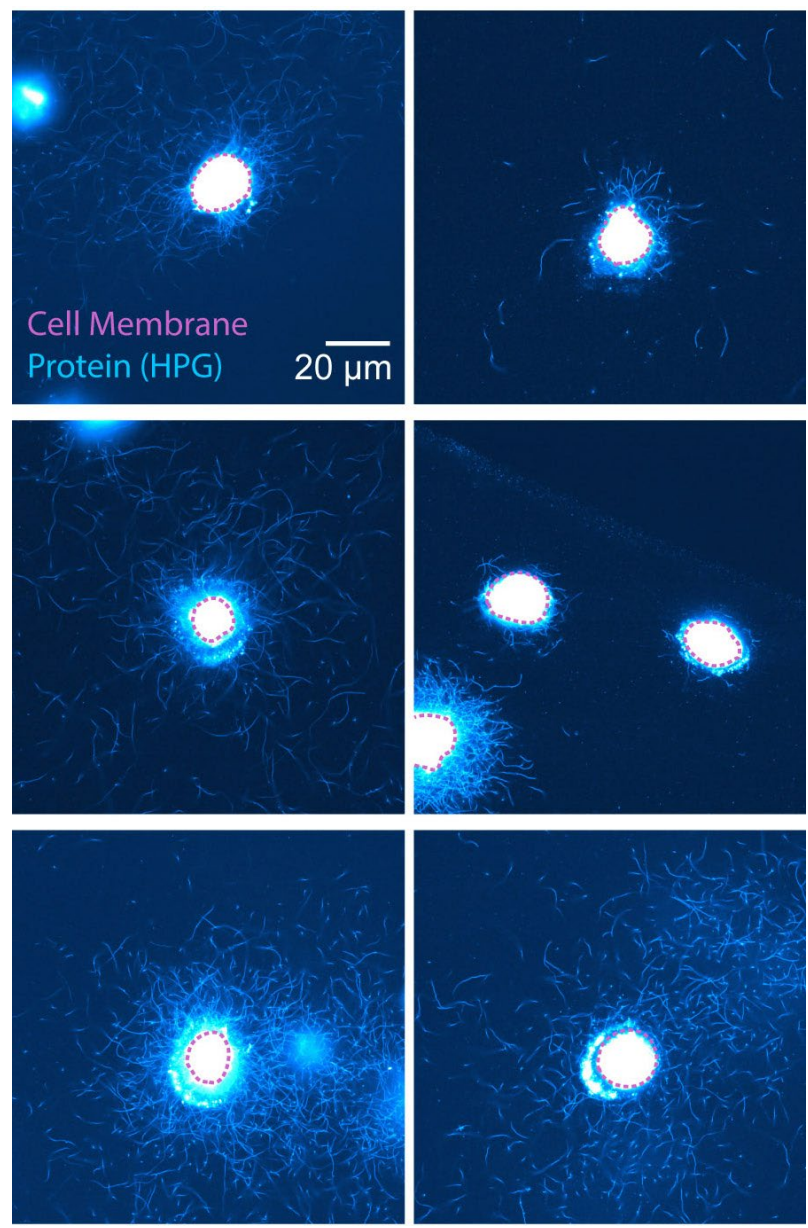

Fig. 3. Example of MSC-to-MSC variation in extracellular matrix production. Confocal crosssections of individual chondrogenically-induced MSCs, metabolically labelled to tag proteinaceous extracellular matrix components (HPG), demonstrate cell-to-cell variability in matrix amount and organisation. Reproduced under the terms of the Creative Commons Attribution License, from McLeod and Mauck, 2016.

a

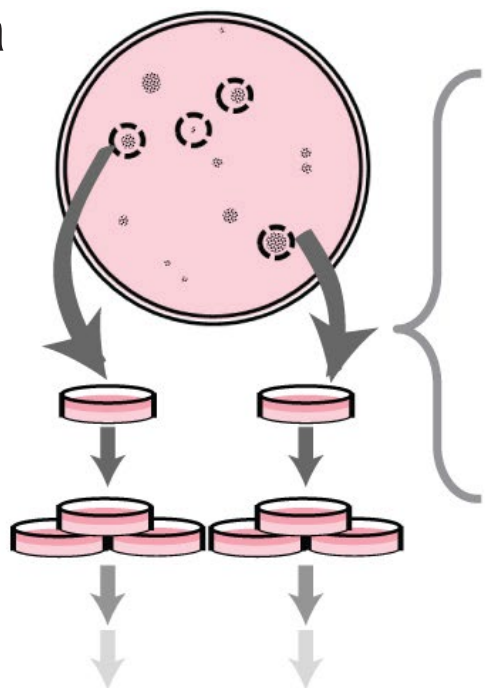

b
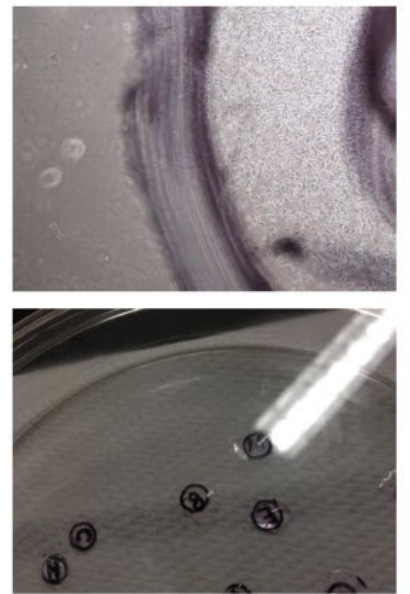
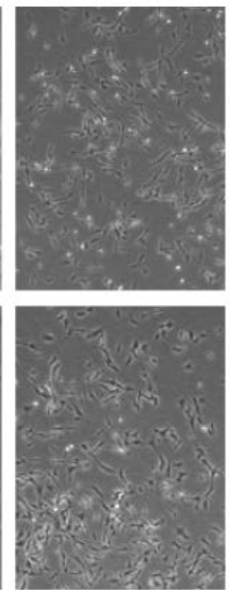
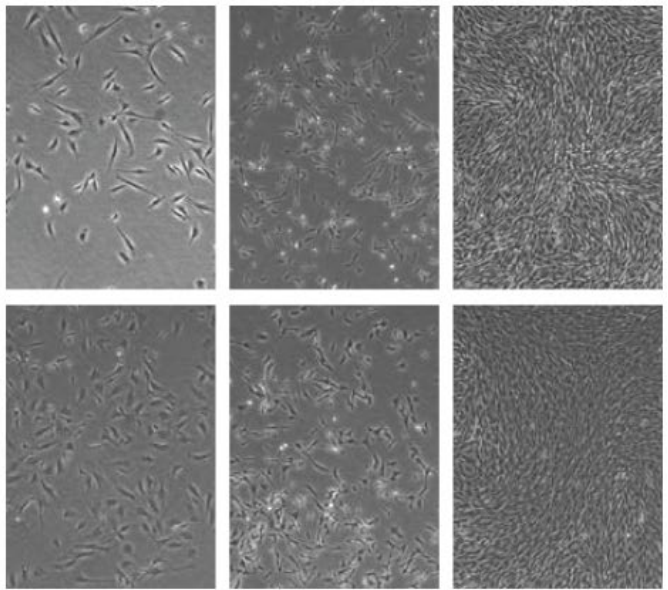

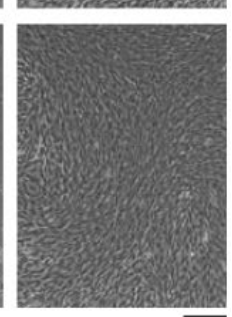

$500 \mu \mathrm{m}$

Fig. 4. Isolating MSC colonies. a) Schematic and photographs of procedure to isolate MSC colonies from the initial plating. Colonies are identified before selective trypsinisation. b) Morphological differences are apparent between MSC colonies in the initial isolate (each image represents a different colony). 
inherent amongst the clone-initiating cells, it develops even further during in vitro culture and population expansion, where expansion on hard tissue culture surfaces may promote such divergence and/or reduction in potency (Li et al., 2017; Yang et al., 2014). Inter-clonal heterogeneity (variation among clones) most obviously manifests as morphological and proliferative diversity. Clones differ in morphological phenotype, ranging from elongated spindle-like cells to large flattened cells and highly protrusive cells (Colter et al., 2001; Muraglia et al., 2000) (Fig. 4). Similarly, individual clones proliferate both more quickly and more slowly than their corresponding polyclonal parent populations and differ in their self-renewal capacity, with select clones reaching early senescence (Russell et al., 2011). These apparent and near-immediate differences in clonal behaviour yield in vitro conditions that vary between clones (e.g. monolayer density) and potentially amplify heterogeneity as the subpopulations further expand.

To summarise, MSC variability is inherent among donors, tissues and clonal subpopulations. Within subpopulations, further variation emerges during culture expansion, and is observable in not only the phenotypic characteristics mentioned above, but also in the functional differentiation capacity, molecular signature and the mechanical state of the cell. The following sections elaborate on these dimensions of emergent heterogeneity.

\section{Inter-clonal functional variation}

The differentiation capacity of clonal MSCs was first studied to prove the existence of multipotent cells capable of committing towards adipogenic, osteogenic and chondrogenic fates (Pittenger et al., 1999). However, evaluation of MSC multipotency has also identified clonal populations that are unresponsive to current differentiation protocols and appear to have restricted differentiation potential (Muraglia et al., 2000; Pittenger et al., 1999; Russell et al., 2010). While the specific fraction of clones that may successfully undergo differentiation is both protocol- and donor- dependent, estimates suggest that $\sim 50 \%$ of clones are tri-potential, $\sim 30 \%$ are bipotential (either osteo-chondro or osteo-adipo), and $\sim 10 \%$ are unipotential osteoprogenitors (Russell et al., 2010).

This functional heterogeneity is also apparent in vivo, and influences the utility of MSCs in multiple regenerative contexts. For example, clonal MSC populations implanted subcutaneously in mice demonstrate variable osteogenic capacity, with only approximately half of clonal implants undergoing some degree of osteogenesis (Kuznetsov et al., 1997). Similarly, clonal populations screened in vitro for above-average chondrogenic capacity result in repair of cartilage defects more robustly than unscreened populations (Jiang et al., 2014). Inter-clonal functional heterogeneity also extends to include commitment towards non-canonical fates. Stem cells derived from dental pulp demonstrate heterogeneous myogenic potential, and clones that are highly myogenic in vitro also engraft into muscle defects more efficaciously than the polyclonal parent populations (Yang et al., 2010). Such functional variability may offer the opportunity to harness clonal identity and prospectively identify MSC subpopulations best suited to drive the functional restoration of a range of tissues. However, the challenge of performing in vitro screening of clonal functional capacity at a clinically-useful scale has motivated ongoing work to identify molecular or biophysical markers of MSC differentiation potential, as will be addressed later in this review.

\section{Inter-clonal molecular variation}

Inter-clonal functional heterogeneity must derive from underlying molecular variation. While proteomic studies comparing individual clonal populations are challenging due to inherently limited cell number, comparisons between pooled fast- and slow-growing clones suggest broad trends. Fast-growing clones are more likely to be tri-potential than slow-growing clones (Mareddy et al., 2007; Russell et al., 2010), and rapidly self-renewing MSCs engrafted into tissues more readily than slowly renewing MSCs (Lee et al., 2006). Indeed, fast- and slow-growing MSCs differ proteomically, with differential expression of proteins including intermediate filaments (e.g. lamin $\mathrm{A} / \mathrm{C})$, calcium-binding proteins (e.g. calmodulin), and glycolytic proteins (e.g. glyceraldehyde-3-phosphate dehydrogenase) (Mareddy et al., 2009). Furthermore, surface marker expression across clones suggest that CD200 marks osteogenic subpopulations, while SSEA4 and CD140a are associated with adipogenic capacity (Pontikoglou et al., 2016; Rostovskaya and Anastassiadis, 2012).

Clonal heterogeneity also extends to the transcriptome. Certainly, there is great divergence in transcriptional signature between high- and lowpotential clones following exposure to differentiation conditions (Mareddy et al., 2010). There is also now evidence for clonal variation in basal gene expression in undifferentiated cells. Screens comparing stem cell gene expression between fast- and slowgrowing clones identify extensive differences in the expression of genes associated with the cell cycle and cellular division (Mareddy et al., 2010; Menicanin et al., 2010). Fast-growing clones also express select growth factors (e.g. BMP2, FGF2, IGF1), lineage markers (e.g. aggrecan, alkaline phosphatase, collagen I, collagen II) and self-renewal markers (e.g. SOX2) more highly than slow-growing clones. Conversely, other genes, including CD44, are more highly expressed in slow-growing clones. Separately, direct comparisons of clonal transcriptomes indicate that clones with greater functional potential have enriched basal expression of genes implicated in skeletal and muscular development, including extracellular matrix components and MAP kinase signalling elements (Elsafadi et al., 2016; Larsen et al., 2010; Sworder et al., 2015). Notably, high baseline 

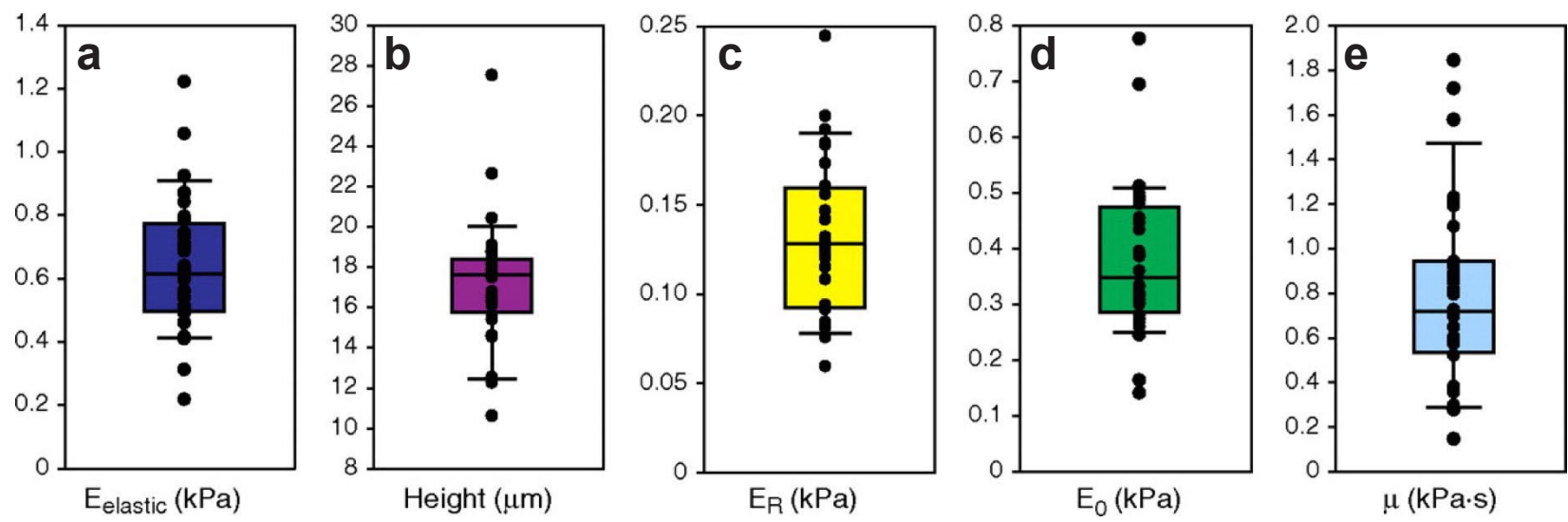

Fig. 5. Heterogeneity in biophysical parameters across 32 MSC clones. a) Elastic modulus, b) cell height, c) relaxed modulus, d) instantaneous modulus, and e) apparent viscosity are presented as the geometric mean of each clone, overlaid on box-whisker plots. Reproduced from González-Cruz et al., 2012.

expression of calponin negatively correlates with clonal multipotency (Sworder et al., 2015). Within an osteogenic context, high potential clones also express extracellular matrix genes and genes regulated by osteogenic transcription factors to a greater extent than poorly osteogenic clones (Larsen et al., 2010). Strikingly, basal expression of four genes, including decorin and lysyl oxidase, is more predictive of clonal osteogenesis than the expression of traditional osteoblastic markers, including Runx2, collagen type I and osteopontin (Larsen et al., 2010). Such findings suggest that transcriptome-wide analysis of undifferentiated MSCs may be key to identifying prospective markers of stem cell fate; however, these predictors must also be validated through mechanistic studies identifying their role in maintenance of multipotency and/or lineage specification.

Transcriptional activity is determined not only by the presence and activity of transcription factors, but also by the epigenetic status of the cell. DNA methylation, one type of epigenetic modification, is generally associated with a loss of gene expression and is crucial in stem cell differentiation. In undifferentiated adult stem cells, lineage-associated promoters are often hypomethylated (Berdasco and Esteller, 2011). Investigation of clonal MSC adipogenesis shows that while adipogenesisassociated promoters are hypomethylated in MSC clones, the specific pattern of methylation varies among clonal subpopulations. Moreover, there is no clear relationship between methylation status and the gene expression pattern or ultimate adipogenic potential for a particular clone (Noer et al., 2006; Noer et al., 2007).

Collectively, these results indicate clear clonal variability in proteomic, transcriptomic and epigenetic status. Correlative relationships between transcriptional status and functional capacity are established at the clonal level, but the identification of any such relationship between a clones' epigenetic marks and differentiation potential remains elusive and require further study across multiple clonal populations.

\section{Biophysical variation amongst clones and individual cells}

The mechanical state of the cell has emerged as another potential biomarker indicative of cellular phenotype. Cellular mechanical properties reflect the underlying structure of the cell, including the cytoskeleton and nucleus. These structures change with differentiation, and also differ among committed cell types. Interestingly, increased nuclear deformability correlates with pluripotency. With differentiation, chromatin condenses within the nucleus and the nuclear envelope is reinforced by increasing lamin A/C content (Heo et al., 2016; Pajerowski et al., 2007). Indeed, embryonic stem cells are 6-10 fold softer than their differentiated counterparts (Chowdhury et al., 2010; Pajerowski et al., 2007). Mechanical differences of similar magnitude have been noted among individual, undifferentiated MSCs isolated and passaged together (Maloney et al., 2010). This mechanical variability may reflect the high degree of functional heterogeneity observed when these individual cells are tasked with a specific lineage transformation.

Mechanical differences also exist among clonal MSC populations. A study monitoring 32 MSC clones suggests that cellular mechanics can be prospectively used to predict differentiation capacity in individual clones (González-Cruz et al., 2012) (Fig. 5). The functional potential of clones correlated with elastic and viscoelastic properties. Clones with the highest adipogenic potential are characterised by taller cells with lower elastic moduli. Conversely, osteogenic capacity correlates with a higher elastic modulus, instantaneous modulus and relaxed modulus, while chondrogenic capacity correlates with elastic modulus and apparent viscosity. Separately, efforts 
to biophysically sort MSCs in a high-throughput manner suggest that the cells of tri-potential MSC subpopulations are smaller, less stiff, and exhibit greater nuclear membrane fluctuations than cells with bi-potent (osteo-chondro) differentiation potential (Lee et al., 2014).

Cell mechanics not only indicate cell phenotype, but also mediate the physical interaction between a cell and its environment. Many cell types, including MSCs, are able to sense and respond to mechanical cues. Biophysical stimuli including the elasticity of the microenvironment and exogenous forces have been widely examined as determinants of stem cell fate (Cosgrove et al., 2016; Engler et al., 2006). These cues elicit changes in biochemical signalling, gene expression, and ultimately cell phenotype and function.

A number of studies have begun to probe how individual MSCs respond to biophysical cues. Dual adipogenic/osteogenic media causes polyclonal MSC populations to undergo mixed osteogenic and adipogenic differentiation; the relative balance between these two differentiated states is regulated by the physical stiffness of the cell microenvironment (Fu et al., 2010; Guvendiren and Burdick, 2012; Khetan et al., 2013). Cell response is most uniform in extremely soft or stiff environments, which favour adipogenesis and osteogenesis respectively. However, in environments of intermediate stiffness, commitment is variable: subpopulations of cells will differentiate towards each fate. Furthermore, in dynamic systems where an initially soft substrate can be stiffened, the ratio of adipogenic to osteogenic commitment is regulated by the timing of the soft-to-stiff transition (Guvendiren and Burdick, 2012). Collectively, these findings suggest that MSC subpopulations may have subtly different mechanical properties that alter the set points at which mechanically-regulated fate commitment occurs.

Any such set point likely relates to the tension sensed and contractility generated by an individual cell. On a population level, osteogenesis is associated with the ability of cells to spread and generate tension, while adipogenesis is promoted by conditions that restrict cell spreading and contractility. Interestingly, the traction force generated by an individual cell after short-term exposure to bipotential media serves as an indicator of its ultimate differentiation propensity: high contractility has been associated with osteogenic potential, while low contractility has been associated with adipogenic capacity (Fu et al., 2010). Thus, single cell or clonal heterogeneity in the ability of cells to generate traction may correspond to the functional variability observed. This also offers the intriguing possibility that adherence and traction against a substrate might be a selection tool to enrich for MSC sub populations with varying differentiation potential.

Variation also extends to cellular activity along the pathways responsible for mechanotransduction.
For example, calcium signalling is highly mechanosensitive, and regulates processes including differentiation and proliferation (Matta and Zakany, 2013). Investigations of baseline calcium signalling in MSCs have shown that some cells exhibit spontaneous calcium oscillations, while others do not (Kawano et al., 2002; Kim et al., 2009; Sun et al., 2007). The extent of variation is microenvironment dependent: the fraction of MSCs experiencing calcium oscillations increases with substrate stiffness, with $59-98 \%$ of cells oscillating on glass culture surfaces (Kawano et al., 2002; Kim et al., 2009; Kim et al., 2014; Sun et al., 2007). Furthermore, this variation extends to the cellular response to active mechanical stimulation. Subpopulations of undifferentiated MSCs encapsulated in hydrogels differentially respond to compression: calcium signalling was upregulated in one subset of cells, while it was downregulated in another (Campbell et al., 2008). It remains to be seen if similar variation extends to other mechano-sensitive pathways, including MAPK and RhoA/ROCK signalling.

To summarise the above points, clonal and individual MSCs differ not only in their inherent mechanical properties, but also in their response to passive and active physical stimuli. These biophysical characteristics correlate with differentiation outcomes, and collectively form an additional dimension of heterogeneity (beyond the molecular characteristics described in the preceding section) and another potential handle by which subpopulation may be selected to increase homogeneity of response for a given application.

\section{Intra-clonal heterogeneity and cell-to-cell variation}

Studies investigating inter-clonal heterogeneity often imply that clonal subpopulations are relatively homogeneous. However, there is growing appreciation that even within a clone, cellular phenotype can be highly variable (Rennerfeldt and Van Vliet, 2016). Cells within a clone can differ in their morphology and ability to differentiate. When intact colonies are exposed to adipogenic or osteogenic differentiation cues, differentiation initiates in the dense, inner portion of the colony (Ylöstalo et al., 2008). Colony micro-dissection and subsequent analysis reveal spatial differences in gene and protein expression. Cells located in the colony interior expressed extracellular matrix genes to a greater extent than cells located in the outer periphery, while "outer" cells expressed higher levels of genes associated with cell proliferation and mitosis (Ylöstalo et al., 2008). Building on this analysis, technological advances have enabled the interrogation of single cell gene expression amongst clonal and polyclonal populations. Single molecule RNA FISH, to assess single cell gene expression within spatially intact MSC clones, suggests that transcriptional variability is pervasive even amongst individual clones (Fig. 6) (Cote et al., 2016). In parallel, RNA FISH and single 
a

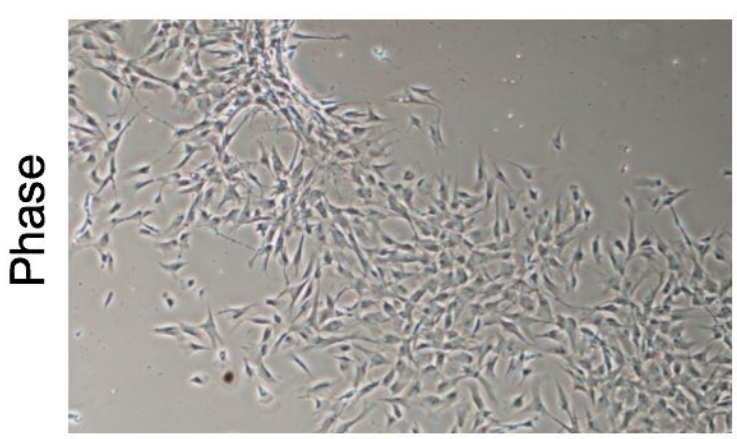

b

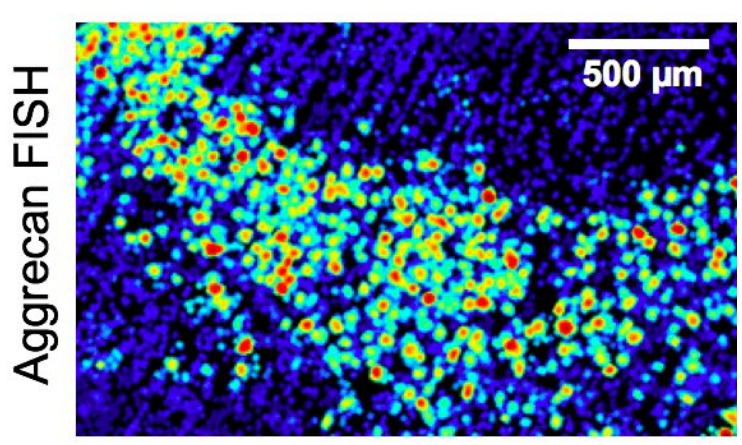

Fig. 6. RNA FISH reveals single cell transcriptional heterogeneity within an individual clone. a) Corresponding phase-contrast and $\mathbf{b}$ ) FISH images, pseudo-coloured such that red indicates high RNA content and blue indicates low RNA content, indicate high intra-clonal variation in gene expression of the chondrogenic marker aggrecan.

cell RNA sequencing of individual MSCs has shown that individual MSCs have variable basal expression of both early and late differentiation markers, and that markers of multiple lineages can be co-expressed in the same cell (Cote et al., 2016; Freeman et al., 2015). Furthermore, DNA methylation patterns are mosaic within individual clonal populations (Noer et al., 2006; Noer et al., 2007). Thus, cell-to-cell variation exists at every level where inter-clonal heterogeneity has been noted, and this must be considered in any basic science study or clinical application that utilises this cell type.

\section{Potential origins \& mechanisms of MSC heterogeneity}

It is tempting to speculate that MSC heterogeneity mirrors the diversity of environments present in the in vivo stem cell niche (Huang, 2009). In vivo, MSCs reside in niches characterised by broad cellular communities that present variable chemical and mechanical conditions. Indeed, micro-anatomical heterogeneity within the bone marrow niche has been shown to dictate cell-to-cell variation in osteolineage cells (Silberstein et al., 2016). Upon isolation, MSCs from these heterogeneous environments mix together, and extant in vivo variation may persist into in vitro cultures. Indeed, there is mounting evidence that cultured cells retain a "memory" of their previous environments (Li et al., 2017; Yang et al., 2014). Furthermore, the mechanical properties of the stem cell microenvironment influence self-renewal capacity and regenerative potential (Gilbert et al., 2010). Perhaps then, the mechanisms responsible for in vitro cellular memory may also facilitate the maintenance of heterogeneity in primary cultures.

In addition to any heterogeneity derived from the in vivo niche, there is also apparent plasticity in the MSC phenotype. In the study of intra-clonal spatial variation discussed above, the subculture of either "inner" or "outer" cells yielded new colonies with their own distinct inner and outer populations, suggesting that, in at least some dimensions, cellular variation is dynamic and reversible (Ylöstalo et al., 2008). Potential dynamics of shifting phenotypic variability have been carefully studied in the context of haematopoietic stem cell (HSC) lineage commitment towards erythroid and myeloid fates. Clonal HSC populations heterogeneously express the surface protein Sca-1, a marker associated with the erythroid transcriptional signature. Subcultures of cells sorted for either the lowest or highest Sca-1 expression shift with time to reconstitute the original distribution of Sca-1 expression (Chang et al., 2008). Similar behaviour is observed in MSCs, which express Sca-1 heterogeneously within and among clonal populations (Hamidouche et al., 2016). At early passage, MSC fractions with either low or high Sca1 expression are able to regenerate the distribution of Sca-1 expression in the parent population (Hamidouche et al., 2016). However, after extended passaging, sorted MSCs are less able to reconstitute the full range of Sca-1 expression (Hamidouche et al., 2016). Potential explanations of this behaviour include spontaneous transcriptional fluctuations (of either transcriptome-wide programs (Chang et al., 2008) or individual regulators (Pina et al., 2012)) and epigenetic bistability (Hamidouche et al., 2016).

Transcriptional fluctuations in the expression of individual genes might arise from the stochasticity inherent to many biological processes. While transcription at the population level is often considered a process that proceeds at a constant, defined rate, transcription in individual cells is highly stochastic. Fundamentally, transcription requires the chemical interaction of RNA polymerases with an accessible promoter sequence and any requisite transcription factors. Thus, even if two stem cells were identical in every way, the transcriptional processes in each would be dictated by the random collisions of molecules within the nuclear milieu. The importance of such probabilistic interactions was elegantly shown in a now-classic experiment 
where two distinguishable, yet near-identical, genes were inserted into a cell (Elowitz et al., 2002). Within individual cells, the expression of these two genes deviated, suggesting the existence of "intrinsic" random noise in gene expression. Notably, this intrinsic noise is superimposed upon any cellto-cell variation controlled by "extrinsic" factors (e.g. epigenetic differences among cells, cell size, etc. - many of the types of variation described in the previous sections). Even so, intrinsic noise can give rise to substantial variation in copy number, and may drive cellular decision-making and phenotypic divergence (Balázsi et al., 2011; Raj and van Oudenaarden, 2008).

Population dynamics also likely contribute to the variation that emerges as the stem cells proliferate in culture. Upon cell division a single, self-renewing, cell splits into two daughter cells of approximately equal size. If the division is symmetrical, both daughter cells will possess the same self-renewal capacity: they will either both divide, or not divide. In contrast, asymmetric cell division will yield one self-renewing cell, and one that senesces in culture. Such dynamics allow an initially small fraction of cells to give rise to the majority of the population several days later. For example, one study reported that after $6 \mathrm{~d}$ of culture, $50 \%$ of progeny cells were derived from $9 \%$ of the initial population (Whitfield et al., 2013). Thus, much of the cell-to-cell variation observed in polyclonal populations may actually be the heterogeneity that emerges from within a single dominant clone. Longer term tracking of MSC lineages over 12 passages confirms this notion of clonal dominance (Selich et al., 2016) (Fig. 7). Interestingly, initially dominant clones are sometimes overtaken by other clonal subpopulations (Selich et al., 2016).

This delayed dominance may be related to variation in the onset of cellular senescence. With extended passage, MSCs suffer from decreased multilineage potential (Digirolamo et al., 1999; Kretlow et al., 2008; Russell et al., 2011; Schellenberg et al., 2011). In parallel, the clonogenicity of MSCs decreases and proliferation slows (Digirolamo et al., 1999; Schellenberg et al., 2011). Functional capacity may also grow increasingly restricted with progressive culture. For example, the hierarchical lineage commitment hypothesis posits that through divisions, stem cells progressively lose the ability to commit to certain lineages. Alternatively, MSC functional heterogeneity may also be explained in part by trans-differentiation, or transitions between partially restricted differentiation capacities (Pevsner-Fischer et al., 2011). The existence, structure, and governance of any such hierarchy or transdifferentiation processes remain to be elucidated (Pevsner-Fischer et al., 2011).

Notably, spontaneous genetic mutations are not thought to be the source of cell-to-cell variation amongst MSCs. Estimates of the mutation rate required to obtain the observed diversity are unfeasibly high: approximately one in three cells

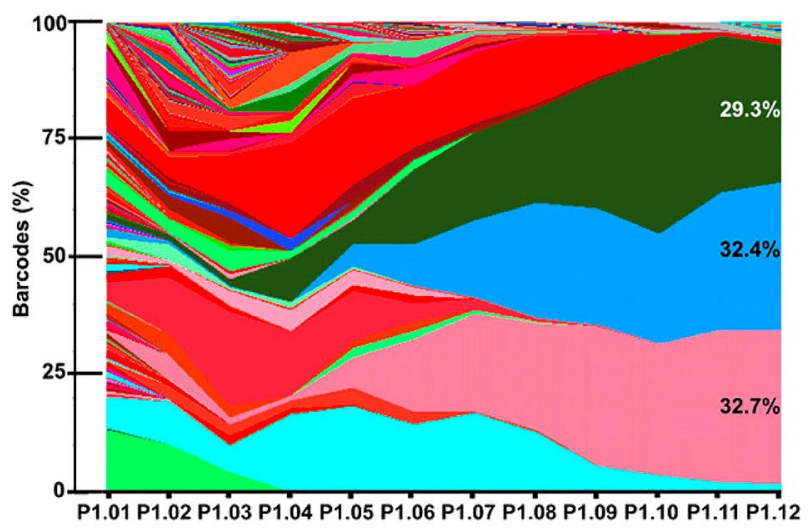

Fig. 7. Clonal dominance amongst MSC during passaging. The relative abundance of barcoded subpopulations shifts with time, as measured in umbilical cord-derived MSCs cultured over 12 passages. Reproduced with permission from Selich et al., 2016.

would need to experience a phenotype-altering mutation (Rennerfeldt and Van Vliet, 2016). While such rates are possible, they are improbable, and thus genetic mutation is unlikely to be a dominant mechanism in the evolution of in vitro MSC heterogeneity (Rennerfeldt and Van Vliet, 2016).

Taken together, the above discussion identifies numerous mechanisms through which heterogeneity may emerge in MSC clonal populations. To identify the timing and mechanism of such changes, however, requires new tools that can operate at the single cell level, the topic of the next section.

\section{Measuring cell-to-cell molecular variation}

Studies to discern the underpinnings of stem cell heterogeneity increasingly rely on methods to assay the molecular content of individual cells. To this end, adaptations of traditional methods and new techniques now allow one to assess gene and protein expression at the single cell level. Broadly, these approaches can be classified on the basis of their timing (continuous observation vs. fixed endpoint), their modality (imaging based vs. lysate based), and their ability to support multiplexed observations (high vs. low). In this section, we highlight select methods that may be of particular utility for assessing stem cell heterogeneity; a summary is provided in Table 1.

\section{Assaying gene expression in single cells}

Single molecule RNA fluorescent in situ hybridisation (FISH) is an imaging-based method that quantifies the absolute amount of mRNA in fixed cells. Sets of fluorescently labelled oligonucleotide probes tile along individual mRNA molecules in a sequencespecific manner, allowing mRNA molecules to be visualised as diffraction-limited spots (Fig. 8a) (Femino et al., 1998; Raj et al., 2008). In standard RNA 
Table 1. Single cell methods to assay mRNA and protein abundance.

\begin{tabular}{|c|c|c|c|}
\hline Method & Timing & Modality & Ability to multiplex \\
\hline \multicolumn{4}{|l|}{ mRNA abundance } \\
\hline RNA FISH & Endpoint & Image based & Low \\
\hline Single cell qPCR & Endpoint & Lysate based & Intermediate \\
\hline Single cell RNA sequencing & Endpoint & Lysate based & High \\
\hline Molecular beacons & Continuous & Image based & Low \\
\hline Spherical nucleic acids & Continuous & Image based & Low \\
\hline Transgenic fluorescent reporters & Continuous & Image based & Low \\
\hline \multicolumn{4}{|c|}{ Protein abundance } \\
\hline Immunostaining & Endpoint & Image based & Low \\
\hline Flow cytometry & Endpoint & Image based & Intermediate \\
\hline Mass cytometry & Endpoint & Lysate based & Intermediate \\
\hline Proximity assays & Endpoint & Lysate based & Low \\
\hline Single cell western blot & Endpoint & Lysate based & Low \\
\hline Single cell mass spec & Endpoint & Lysate based & High \\
\hline Transgenic fluorescent reporters & Continuous & Image based & Low \\
\hline
\end{tabular}

\section{a) RNA FISH}

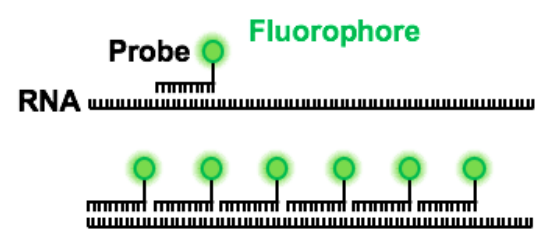

c) Spherical nucleic acids

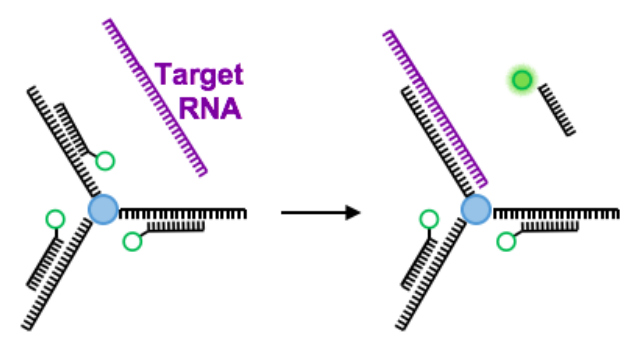

b) Molecular beacons

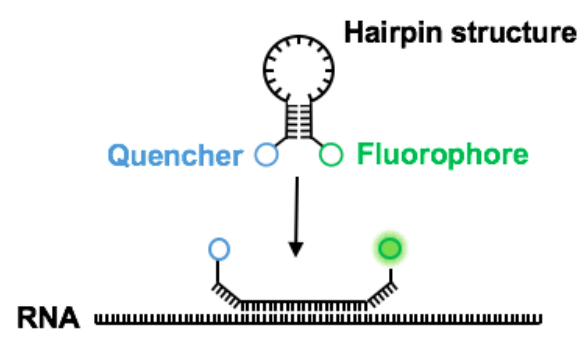

\section{d) MS2 system}

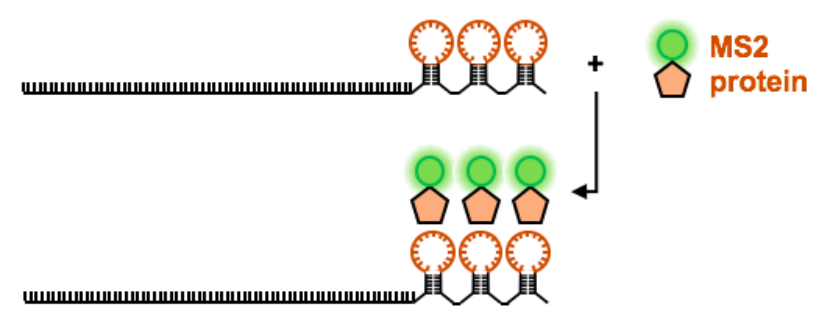

Fig. 8. Schematics of select methods to measure mRNA in single cells. a) In RNA FISH, fluorescently labelled oligonucleotide probes tile along the target mRNA. b) Molecular beacons emit fluorescence upon binding to target mRNA. c) Spherical nucleic acids quench fluorescence until target mRNA binding occurs. d) In the MS2 system, fluorescently tagged proteins bind to motifs engineered into the mRNA sequence. Adapted by permission from Macmillan Publishers Ltd: Nature Cell Biology, Hoppe et al., copyright 2014.

FISH, the number of genes simultaneously assayed is restricted by the availability of microscope filter sets (approximately 4 genes). However, recent strategies utilising combinatorial and sequential barcoding substantially increase the potential number of genes measured (Lubeck et al., 2014; Lubeck and Cai, 2012).

Other endpoint methods for assaying single cell gene expression include single cell RT-qPCR, microarrays, and RNA-seq (Saliba et al., 2014; Ståhlberg and Bengtsson, 2010). Each of these approaches measures the abundance of cDNA amplified from mRNA in the lysates of individual cells. The ability of single cell RNA-seq to report transcriptome-wide expression holds particular promise as the field develops an increased understanding of the many dimensions of cell-to-cell variation. However, these 
methods also require normalisation (vs. absolute quantification), and cannot provide information about the spatial distribution of individual mRNA within an individual cell.

Alternative techniques allow gene expression to be monitored continuously in live cultures through imaging. Strategies such as molecular beacons and spherical nucleic acids (e.g. nanoflares) rely on oligonucleotides, fluorophores, and fluorescent quenchers to report gene expression (Fig. 8b,c) (Seferos et al., 2007; Tyagi and Kramer, 1996). When the oligonucleotide probe binds to a target mRNA, the quencher separates from the fluorophore and permits fluorescent signalling. These methods are used to monitor gene expression in live MSCs undergoing osteogenesis, and can be combined with FACS techniques to sort individual cells on the basis of their gene expression (Fig. 9) (Li et al., 2016; Marble et al., 2014).

Other efforts to monitor gene expression in realtime rely on transgenic methods. Expression of genes modified to include repetitive stem-loop motifs can be monitored using fluorescent bacteriophage proteins that bind to these sequences with high affinity (Fig. 8d) (Fusco et al., 2003; Shav-Tal et al., 2004). Alternatively, short-lived fluorescent reporter proteins are considered as proxies for the expression of genes under the control of the same promoter (Suter et al., 2011).

\section{Assaying protein expression in single cells}

In addition to quantifying mRNA at the single cell level, it is also essential to map and measure the protein output from this message content on a cellby-cell basis. Single cell measurements of protein expression are possible using a variety of techniques, many of which rely on antibody-based detection. The simplest of these is standard immunostaining, imaged at high magnification and quantified on a per-cell basis. Flow cytometry offers high throughput measurements of fluorescent antibody signal, and can be coupled with cell sorting and multiplexed to accommodate the measurement of $10-15$ proteins (Spitzer et al., 2016). Mass cytometry allows further multiplexing by leveraging mass spectroscopy to detect the levels of metallically-conjugated antibodies bound to individual cells (Spitzer et al., 2016). Recently, imaging mass spectrometry has further extended this approach to enable the measurement of protein abundance in histological sections while preserving spatial information (Chang et al., 2017).

An additional category of assays includes those based on proximity, including proximity ligation (PLA) and proximity extension (PEA). In these approaches, pairs of antibodies conjugated to oligonucleotides are used to probe cell lysates (Greenwood et al., 2015). When an antibody pair binds to the protein of interest, the two oligos are brought together and either ligated (PLA) or hybridised (PEA) to create a template for the synthesis of reporter DNA that is ultimately detected using qPCR or sequencing (Greenwood et al., 2015). Interestingly, this method is compatible with lysate-based assays of single cell gene expression, and has recently been used to simultaneously examine the proteomic and transcriptomic state of single cells (Darmanis et al., 2016).

Techniques for assaying protein expression in bulk lysates have also recently been scaled down to accommodate single cells. Western blots can be performed on individual cells that have settled into microwells in a polyacrylamide gel; the cells are lysed in their wells immediately prior to in-gel electrophoresis, blotting and detection (Hughes et al., 2014; Kang et al., 2016). There is also active development surrounding single cell mass spectrometry, which was recently used to quantify the abundance of thousands of proteins at the single cell level during embryonic stem cell differentiation (Budnik et al., 2017 - non-peer reviewed e-publication). a

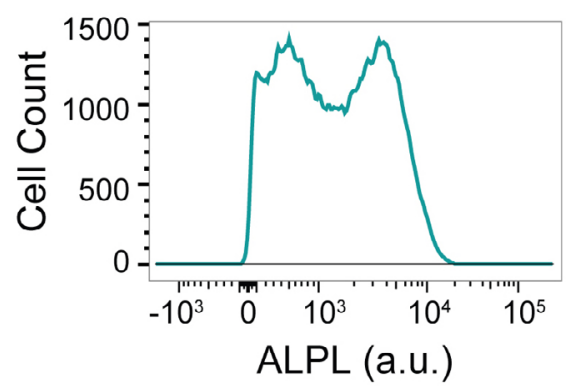

b

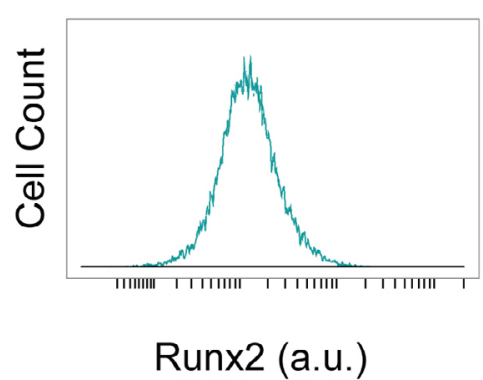

C

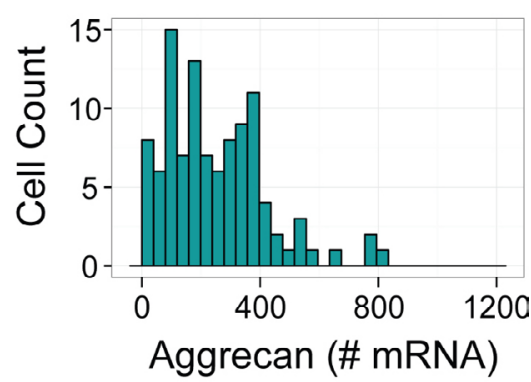

Fig. 9. Multiple techniques identify high cell-to-cell variation in single cell gene expression amongst individual MSCs. a) Molecular beacons (Marble et al. 2014), b) spherical nucleic acids (Li et al. 2016) and c) single molecule RNA FISH (Cote et al. 2016) have been used to query the single cell abundance of various differentiation markers (ALPL, Runx2 and ACAN, respectively). Subfigures reproduced under the terms of the Creative Commons Attribution License. 


\section{Conclusions \& Outlook}

Mesenchymal stem cells demonstrate many dimensions of heterogeneity: they differ among donors, as well as among and within clonal populations. Indeed, cell-to-cell variation seems inherent to the cell type, and we speculate that heterogeneity will be found in every place it is sought. The facets of MSC variability discussed here are non-exhaustive, and even within the categories reviewed, we have highlighted only a subset of relevant studies. Moreover, even papers that do not specifically discuss heterogeneity are impacted by its presence in their cell populations, though this may be underappreciated in the community.

Given the pervasiveness of MSC variability, how can we as a community best acknowledge and respond? As a first step, we recommend that, whenever possible, studies performed at the population level should be validated in terms of the principal findings using clonally expanded populations. This would clarify whether the response is universal to all MSCs, or only to selected subpopulations. A second approach would be to screen cells prior to use in experiments (e.g. by FACS or mechanical sorting), to more precisely understand the properties of the cells being used, and potentially select for specific subpopulations. As our understanding of heterogeneity grows, such selection strategies may become more refined and easy to implement, and eventually standard for the field.

With respect to the emergence of genome-wide single cell techniques, these hold the potential to identify new molecular targets that vary among cells and correspond to differences in functional potential. However, as our technological ability to interrogate biology at the single cell level grows, we will also need to distinguish biological noise from variation that represents actionable signal. Our ability to discern such signal may be enhanced by the choice of measurement approach. For example, biological noise often has a temporal component (e.g. stochastic gene expression fluctuations). In these situations, endpoint measurements may reveal substantial variation, even if cells' time-averaged behaviour is similar. In contrast, continuous measurements could be integrated or averaged over time to potentially smooth stochastic temporal fluctuations while retaining evidence of major cell-to-cell variation. Regardless of measurement technique, the further study of MSC variation holds the potential to clarify the mechanisms and implications of cell-to-cell heterogeneity.

From a clinical perspective, heightened appreciation of MSC variation may also ultimately improve the efficacy of regenerative medicine applications. If we are able to succeed in identifying determinants or correlates of an individual cell's propensity to differentiate along a specified lineage, it may be feasible to either select for the best cells, or deplete the worst. Such enrichment techniques would ideally be implementable at the time of treatment, and most ideally during the time frame of a normal surgery, so that these technologies could be applied without undo cell manipulation. However, the most efficient sorting may require priming of the population prior to implementation so as to sufficiently distinguish between high- and low-performing cells. Short of this, when we interpret MSC functionality relative to other cell types, we could consider not only total cell number, but also the fraction of MSCs expected to exhibit the desired performance; this may guide dosing guidelines for clinical applications.

Taken together, this review outlines the many dimensions and potential mechanisms in which mesenchymal stem cells exhibit heterogeneity. We also outline emerging tools, working at the single cell level, which may shed new light on the mechanisms that govern the emergence and persistence of such heterogeneity in these populations. Once understood more completely, sorting and selection may be tractable, in a cost-efficient and practical fashion, ultimately improving the clarity and efficacy with which MSC-based therapeutics are understood and applied.

\section{Acknowledgements}

This work was funded by the National Institutes of Health (R01 EB008722, T32 HL007954) and the Penn Center for Musculoskeletal Disorders (P30 AR069619). We thank Dr. Megan Farrell for providing the images depicted in Fig. 4 and 6, and Todd Curtis for schematic illustrations in Fig. 2.

\section{References}

Altschuler SJ, Wu LF (2010) Cellular heterogeneity: do differences make a difference? Cell 141: 559-563.

Balázsi G, van Oudenaarden A, Collins JJ (2011) Cellular decision making and biological noise: from microbes to mammals. Cell 144: 910-925.

Berdasco M, Esteller M (2011) DNA methylation in stem cell renewal and multipotency. Stem Cell Res Ther. 2: 42.

Bourin P, Bunnell BA, Casteilla L, Dominici M, Katz AJ, March KL, Redl H, Rubin JP, Yoshimura K, Gimble JM (2013) Stromal cells from the adipose tissue-derived stromal vascular fraction and culture expanded adipose tissue-derived stromal/stem cells: a joint statement of the International Federation for Adipose Therapeutics and Science (IFATS) and the International Society for Cellular Therapy (ISCT). Cytotherapy 15: 641-648.

Budnik B, Levy E, Slavov N (2017) Massspectrometry of single mammalian cells quantifies proteome heterogeneity during cell differentiation. 
bioRxiv: doi:10.1101/102681 (non-peer reviewed e-publication).

Campbell J, Bader D, Lee D (2008) Mechanical loading modulates intracellular calcium signaling in human mesenchymal stem cells. J Appl Biomater Biomech 6: 9-15.

Chang HH, Hemberg M, Barahona M, Ingber DE, Huang S (2008) Transcriptome-wide noise controls lineage choice in mammalian progenitor cells. Nature 453: 544-547.

Chang Q, Ornatsky OI, Siddiqui I, Loboda A, Baranov VI, Hedley DW (2017) Imaging mass cytometry. Cytometry A 91: 160-169.

Chowdhury F, Na S, Li D, Poh Y-C, Tanaka TS, Wang F, Wang N (2010) Material properties of the cell dictate stress-induced spreading and differentiation in embryonic stem cells. Nat Mater. 9: 82-88.

Colter DC, Sekiya I, Prockop DJ (2001) Identification of a subpopulation of rapidly self-renewing and multipotential adult stem cells in colonies of human marrow stromal cells. Proc Natl Acad Sci. U S A 98: 7841-7845.

Cosgrove BD, Mui KL, Driscoll TP, Caliari SR, Mehta KD, Assoian RK, Burdick JA, Mauck RL (2016) N-cadherin adhesive interactions modulate matrix mechanosensing and fate commitment of mesenchymal stem cells. Nat Mater 15: 1297-1306.

Cote AJ, McLeod CM, Farrell MJ, McClanahan PD, Dunagin MC, Raj A, Mauck RL (2016) Single-cell differences in matrix gene expression do not predict matrix deposition. Nat Commun 7: 10865.

D'Ippolito G, Schiller PC, Ricordi C, Roos BA, Howard GA (1999) Age-related osteogenic potential of mesenchymal stromal stem cells from human vertebral bone marrow. J Bone Miner Res. 14: 11151122.

Darmanis S, Gallant CJ, Marinescu VD, Niklasson M, Segerman A, Flamourakis G, Fredriksson S, Assarsson E, Lundberg M, Nelander S, Westermark B, Landegren U (2016) Simultaneous multiplexed measurement of RNA and proteins in single cells. Cell Rep. 14: 380-389.

Digirolamo C, Stokes D, Colter D, Phinney D, Class R, Prockop D (1999) Propagation and senescence of human marrow stromal cells in culture: a simple colony-forming assay identifies samples with the greatest potential to propagate and differentiate. $\mathrm{Br}$ J Haematol 107: 275-281.

Dominici M, Le Blanc K, Mueller I, SlaperCortenbach I, Marini F, Krause D, Deans R, Keating A, Prockop D, Horwitz E (2006) Minimal criteria for defining multipotent mesenchymal stromal cells. The International Society for Cellular Therapy position statement. Cytotherapy 8: 315-317.

Elowitz MB, Levine AJ, Siggia ED, Swain PS (2002) Stochastic gene expression in a single cell. Science 297: 1183-1186.

Elsafadi M, Manikandan M, Atteya M, Hashmi JA, Iqbal Z, Aldahmash A, Alfayez M, Kassem M, Mahmood A (2016) Characterization of cellular and molecular heterogeneity of bone marrow stromal cells. Stem Cells Int. 2016: 1-18.

Engler AJ, Sen S, Sweeney HL, Discher DE (2006) Matrix elasticity directs stem cell lineage specification. Cell 126: 677-689.

Erices A, Conget P, Minguell JJ (2000) Mesenchymal progenitor cells in human umbilical cord blood. Br J Haematol 109: 235-242.

Estes BT, Diekman BO, Gimble JM, Guilak F (2010) Isolation of adipose-derived stem cells and their induction to a chondrogenic phenotype. Nat Protoc 5: 1294-1311.

Femino AM, Fay FS, Fogarty K, Singer RH (1998) Visualization of single RNA transcripts in situ. Science 280: 585-590.

Freeman BT, Jung JP, Ogle BM (2015) Single-cell RNA-Seq of bone marrow-derived mesenchymal stem cells reveals unique profiles of lineage priming. PLoS One 10: e0136199.

Friedenstein AJ (1976) Precursor cells of mechanocytes. Int Rev Cytol 47: 327-359.

Fu J, Wang Y-K, Yang MT, Desai R a, Yu X, Liu Z, Chen CS (2010) Mechanical regulation of cell function with geometrically modulated elastomeric substrates. Nat Methods 7: 733-736.

Fusco D, Accornero N, Lavoie B, Shenoy SM, Blanchard JM, Singer RH, Bertrand E (2003) Single mRNA molecules demonstrate probabilistic movement in living mammalian cells. Curr Biol 13: 161-167.

Gilbert PM, Havenstrite KL, Magnusson KEG, Sacco A, Leonardi NA, Kraft P, Nguyen NK, Thrun S, Lutolf MP, Blau HM (2010) Substrate elasticity regulates skeletal muscle stem cell self-renewal in culture. Science 329: 1078-1081.

González-Cruz RD, Fonseca VC, Darling EM (2012) Cellular mechanical properties reflect the differentiation potential of adipose-derived mesenchymal stem cells. Proc Natl Acad Sci U S A 109: E1523-1529.

Greenwood C, Ruff D, Kirvell S, Johnson G, Dhillon HS, Bustin SA (2015) Proximity assays for sensitive quantification of proteins. Biomol Detect Quantif 4: 10-16.

Gronthos S, Mankani M, Brahim J, Robey PG, Shi S (2000) Postnatal human dental pulp stem cells (DPSCs) in vitro and in vivo. Proc Natl Acad Sci U S A 97: 13625-13630.

Guvendiren M, Burdick JA (2012) Stiffening hydrogels to probe short- and long-term cellular responses to dynamic mechanics. Nat Commun 3: 792.

Hamidouche Z, Rother K, Przybilla J, Krinner A, Clay D, Hopp L, Fabian C, Stolzing A, Binder H, Charbord P, Galle J (2016) Bistable epigenetic states explain age-dependent decline in mesenchymal stem cell heterogeneity. Stem Cells 35: 694-704.

Heo S-J, Driscoll TP, Thorpe SD, Nerurkar NL, Baker BM, Yang MT, Chen CS, Lee DA, Mauck RL (2016) Differentiation alters stem cell nuclear 
architecture, mechanics, and mechano-sensitivity. Elife 5: 283-293.

Hoppe PS, Coutu DL, Schroeder T (2014) Singlecell technologies sharpen up mammalian stem cell research. Nat Cell Biol. 16: 919-927.

Huang AH, Farrell MJ, Mauck RL (2010) Mechanics and mechanobiology of mesenchymal stem cell-based engineered cartilage. J Biomech 43: 128-136.

Huang S (2009) Non-genetic heterogeneity of cells in development: more than just noise. Development 136: 3853-3862.

Hughes AJ, Spelke DP, Xu Z, Kang C-C, Schaffer D V, Herr AE (2014) Single-cell western blotting. Nat Methods 11: 749-755.

Jiang L, Ma A, Song L, Hu Y, Dun H, Daloze P, Yu Y, Jiang J, Zafarullah M, Chen H (2014) Cartilage regeneration by selected chondrogenic clonal mesenchymal stem cells in the collagenase- induced monkey osteoarthritis model. J Tissue Eng Regen Med 8: 896-905.

Johnstone B, Hering TM, Caplan AI, Goldberg VM, Yoo JU (1998) In vitro chondrogenesis of bone marrow-derived mesenchymal progenitor cells. Exp Cell Res 238: 265-272.

Johnstone B, Alini M, Cucchiarini M, Dodge GR, Eglin D, Guilak F, Madry H, Mata A, Mauck RL, Semino CE, Stoddart MJ (2013) Tissue engineering for articular cartilage repair - the state of the art. Eur Cell Mater 25: 248-267.

Kang C-C, Yamauchi KA, Vlassakis J, Sinkala E, Duncombe TA, Herr AE (2016) Single cell-resolution western blotting. Nat Protoc 11: 1508-1530.

Katsara O, Mahaira LG, Iliopoulou EG, Moustaki A, Antsaklis A, Loutradis D, Stefanidis K, Baxevanis CN, Papamichail M, Perez SA (2011) Effects of donor age, gender, and in vitro cellular aging on the phenotypic, functional, and molecular characteristics of mouse bone marrow-derived mesenchymal stem cells. Stem Cells Dev 20: 1549-1561.

Kawano S, Shoji S, Ichinose S, Yamagata K, Tagami M, Hiraoka M (2002) Characterization of $\mathrm{Ca}(2+)$ signaling pathways in human mesenchymal stem cells. Cell Calcium 32: 165-174.

Kern S, Eichler H, Stoeve J, Klüter H, Bieback K (2006) Comparative analysis of mesenchymal stem cells from bone marrow, umbilical cord blood, or adipose tissue. Stem Cells 24: 1294-1301.

Khetan S, Guvendiren M, Legant WR, Cohen DM, Chen CS, Burdick JA (2013) Degradation-mediated cellular traction directs stem cell fate in covalently crosslinked three-dimensional hydrogels. Nat Mater 12: 458-465.

Kim T-J, Seong J, Ouyang M, Sun J, Lu S, Hong JP, Wang N, Wang Y (2009) Substrate rigidity regulates $\mathrm{Ca} 2+$ oscillation via RhoA pathway in stem cells. J Cell Physiol 218: 285-293.

Kim T-J, Sun J, Lu S, Qi Y-X, Wang Y (2014) Prolonged mechanical stretch initiates intracellular calcium oscillations in human mesenchymal stem cells. PLoS One 9: e109378.
Kock L, van Donkelaar CC, Ito K (2012) Tissue engineering of functional articular cartilage: the current status. Cell Tissue Res 347: 613-627.

Kretlow JD, Jin Y-Q, Liu W, Zhang WJ, Hong T-H, Zhou G, Baggett LS, Mikos AG, Cao Y (2008) Donor age and cell passage affects differentiation potential of murine bone marrow-derived stem cells. BMC Cell Biol. 9: 60.

Kuznetsov SA, Krebsbach PH, Satomura K, Kerr J, Riminucci M, Benayahu D, Robey PG (1997) Singlecolony derived strains of human marrow stromal fibroblasts form bone after transplantation in vivo. J Bone Miner Res 12: 1335-1347.

Kuznetsov SA, Mankani MH, Bianco P, Robey PG (2009) Enumeration of the colony-forming unitsfibroblast from mouse and human bone marrow in normal and pathological conditions. Stem Cell Res 2: 83-94.

Larsen KH, Frederiksen CM, Burns JS, Abdallah BM, Kassem M (2010) Identifying a molecular phenotype for bone marrow stromal cells with in vivo bone forming capacity. J Bone Miner Res. 25: 796-808.

Lee RH, Hsu SC, Munoz J, Jung JS, Lee NR, Pochampally R, Prockop DJ (2006) A subset of human rapidly self-renewing marrow stromal cells preferentially engraft in mice. Blood 107: 2153-2161.

Lee WC, Shi H, Poon Z, Nyan LM, Kaushik T, Shivashankar G V., Chan JKY, Lim CT, Han J, Van Vliet KJ (2014) Multivariate biophysical markers predictive of mesenchymal stromal cell multipotency. Proc Natl Acad Sci U S A 111: E4409-E4418.

Li B, Menzel U, Loebel C, Schmal H, Alini M, Stoddart MJ (2016) Monitoring live human mesenchymal stromal cell differentiation and subsequent selection using fluorescent RNA-based probes. Sci Rep 6: 26014.

Li CX, Talele NP, Boo S, Koehler A, Knee-Walden E, Balestrini JL, Speight P, Kapus A, Hinz B (2017) MicroRNA-21 preserves the fibrotic mechanical memory of mesenchymal stem cells. Nat Mater 16: 379-389.

Lubeck E, Cai L (2012) Single-cell systems biology by super-resolution imaging and combinatorial labeling. Nat Methods 9: 743-748.

Lubeck E, Coskun AF, Zhiyentayev T, Ahmad M, Cai L (2014) Single-cell in situ RNA profiling by sequential hybridization. Nat Methods 11: 360-361.

Maloney JM, Nikova D, Lautenschläger F, Clarke E, Langer R, Guck J, Van Vliet KJ (2010) Mesenchymal stem cell mechanics from the attached to the suspended state. Biophys J 99: 2479-2487.

Marble HD, Sutermaster BA, Kanthilal M, Fonseca VC, Darling EM (2014) Gene expression-based enrichment of live cells from adipose tissue produces subpopulations with improved osteogenic potential. Stem Cell Res Ther 5: 145.

Mareddy S, Broadbent J, Crawford R, Xiao Y (2009) Proteomic profiling of distinct clonal populations of bone marrow mesenchymal stem cells. J Cell Biochem 106: 776-786. 
Mareddy S, Crawford R, Brooke G, Xiao Y (2007) Clonal isolation and characterization of bone marrow stromal cells from patients with osteoarthritis. Tissue Eng 13: 819-829.

Mareddy S, Dhaliwal N, Crawford R, Xiao Y (2010) Stem cell-related gene expression in clonal populations of mesenchymal stromal cells from bone marrow. Tissue Eng. Part A 16: 749-758. doi:10.1089/ ten.TEA.2009.0307.

Matta C, Zakany R (2013) Calcium signalling in chondrogenesis: implications for cartilage repair. Front Biosci (Schol Ed). 5: 305-324.

Mattar P, Bieback K (2015) Comparing the immunomodulatory properties of bone marrow, adipose tissue, and birth-associated tissue mesenchymal stromal cells. Front Immunol 6: 560.

McLeod CM, Mauck RL (2016) High fidelity visualization of cell-to-cell variation and temporal dynamics in nascent extracellular matrix formation. Sci. Rep. 6: 38852.

Menicanin D, Bartold PM, Zannettino ACW, Gronthos S (2010) Identification of a common gene expression signature associated with immature clonal mesenchymal cell populations derived from bone marrow and dental tissues. Stem Cells Dev 19: 15011510.

Mindaye ST, Lo Surdo J, Bauer SR, Alterman MA (2015) The proteomic dataset for bone marrow derived human mesenchymal stromal cells: Effect of in vitro passaging. Data Brief 5: 864-870.

Mindaye ST, Ra M, Lo Surdo JL, Bauer SR, Alterman M (2013) Global proteomic signature of undifferentiated human bone marrow stromal cells: evidence for donor-to-donor proteome heterogeneity. Stem Cell Res 11: 793-805.

Muraglia A, Cancedda R, Quarto R (2000) Clonal mesenchymal progenitors from human bone marrow differentiate in vitro according to a hierarchical model. J Cell Sci 113: 1161-1166.

Noer A, Boquest AC, Collas P (2007) Dynamics of adipogenic promoter DNA methylation during clonal culture of human adipose stem cells to senescence. BMC Cell Biol 8: 18.

Noer A, Sørensen AL, Boquest AC, Collas P (2006) Stable CpG hypomethylation of adipogenic promoters in freshly isolated, cultured, and differentiated mesenchymal stem cells from adipose tissue Mol Biol Cell 17: 3543-3556.

Pajerowski J, Dahl K, Zhong F (2007) Physical plasticity of the nucleus in stem cell differentiation. Proc Natl Acad Sci U S A 104: 15619-15624.

Pevsner-Fischer M, Levin S, Zipori D (2011) The origins of mesenchymal stromal cell heterogeneity. Stem Cell Rev 7: 560-568.

Phinney DG, Kopen G, Righter W, Webster S, Tremain N, Prockop DJ (1999) Donor variation in the growth properties and osteogenic potential of human marrow stromal cells. J Cell Biochem 75: 424-436.

Pina C, Fugazza C, Tipping AJ, Brown J, Soneji S, Teles J, Peterson C, Enver T (2012) Inferring rules of lineage commitment in haematopoiesis. Nat Cell Biol 14: 287-294.

Pittenger MF, Mackay A, Beck SC, Jaiswal R, Douglas R, Mosca J, Moorman M, Simonetti D, Craig S, Marshak D (1999) Multilineage potential of adult human mesenchymal stem cells. Science 284: 143-147.

Pontikoglou C, Langonné A, Ba MA, Varin A, Rosset P, Charbord P, Sensébé L, Deschaseaux F (2016) CD200 expression in human cultured bone marrow mesenchymal stem cells is induced by proosteogenic and pro-inflammatory cues. J Cell Mol Med 20: 655-665.

Raj A, van den Bogaard P, Rifkin SA, van Oudenaarden A, Tyagi S (2008) Imaging individual mRNA molecules using multiple singly labeled probes. Nat Methods 5: 877-879.

Raj A, van Oudenaarden A (2008) Nature, nurture, or chance: stochastic gene expression and its consequences. Cell 135: 216-226.

Rennerfeldt DA, Van Vliet KJ (2016) Concise review: when colonies are not clones: evidence and implications of intracolony heterogeneity in mesenchymal stem cells. Stem Cells 34: 1135-1141.

Rostovskaya M, Anastassiadis K (2012) Differential expression of surface markers in mouse bone marrow mesenchymal stromal cell subpopulations with distinct lineage commitment. PLoS One 7: e51221.

Russell KC, Lacey MR, Gilliam JK, Tucker HA, Phinney DG, O'Connor KC (2011) Clonal analysis of the proliferation potential of human bone marrow mesenchymal stem cells as a function of potency. Biotechnol Bioeng 108: 2716-2726.

Russell KC, Phinney DG, Lacey MR, Barrilleaux BL, Meyertholen KE, O'Connor KC (2010) In vitro high-capacity assay to quantify the clonal heterogeneity in trilineage potential of mesenchymal stem cells reveals a complex hierarchy of lineage commitment. Stem Cells 28: 788-798.

Saliba A-E, Westermann AJ, Gorski SA, Vogel J (2014) Single-cell RNA-seq: advances and future challenges. Nucleic Acids Res 42: 8845-8860.

Schellenberg A, Lin Q, Schüler H, Koch CM, Joussen S, Denecke B, Walenda G, Pallua N, Suschek C V, Zenke M, Wagner W (2011) Replicative senescence of mesenchymal stem cells causes DNAmethylation changes which correlate with repressive histone marks. Aging (Albany NY) 3: 873-888.

Seferos D, Giljohann D, Hill H, Prigodich A, Mirkin C (2007) Nano-flares: probes for transfection and mRNA detection in living cells. J Am Chem Soc 129:15477-15479.

Selich A, Daudert J, Hass R, Philipp F, von Kaisenberg C, Paul G, Cornils K, Fehse B, Rittinghausen S, Schambach A, Rothe M (2016) Massive clonal selection and transiently contributing clones during expansion of mesenchymal stem cell cultures revealed by lentiviral RGB-barcode technology. Stem Cells Transl Med 5: 591-601.

Shav-Tal Y, Darzacq X, Shenoy SM, Fusco D, Janicki SM, Spector DL, Singer RH (2004) Dynamics 
of single mRNPs in nuclei of living cells. Science 304: 1797-1800.

Silberstein L, Goncalves KA, Kharchenko PV, Turcotte R, Kfoury Y, Mercier F, Baryawno N, Severe N, Bachand J, Spencer JA, Papazian A, Lee D, Chitteti BR, Srour EF, Hoggatt J, Tate T, Lo Celso C, Ono N, Nutt S, Heino J, Sipilä K, Shioda T, Osawa M, Lin CP, Hu G, Scadden DT (2016) Proximity-based differential single-cell analysis of the niche to identify stem/progenitor cell regulators. Cell Stem Cell 19: 530-543.

Smith JR, Pochampally R, Perry A, Hsu S-C, Prockop DJ (2004) Isolation of a highly clonogenic and multipotential subfraction of adult stem cells from bone marrow stroma. Stem Cells 22: 823-831.

Spitzer MH, Nolan GP (2016) Mass cytometry: single cells, many features. Cell 165: 780-791.

Ståhlberg A, Bengtsson M (2010) Single-cell gene expression profiling using reverse transcription quantitative real-time PCR. Methods 50: 282-288.

Stenderup K, Justesen J, Clausen C, Kassem M (2003) Aging is associated with decreased maximal life span and accelerated senescence of bone marrow stromal cells. Bone 33: 919-926.

Strioga M, Viswanathan S, Darinskas A, Slaby O, Michalek J (2012) Same or not the same? Comparison of adipose tissue-derived versus bone marrowderived mesenchymal stem and stromal cells. Stem Cells Dev 21: 2724-2752.

Sun S, Liu Y, Lipsky S, Cho M (2007) Physical manipulation of calcium oscillations facilitates osteodifferentiation of human mesenchymal stem cells. FASEB J 21: 1472-1480.

Suter DM, Molina N, Gatfield D, Schneider K, Schibler U, Naef F (2011) Mammalian genes are transcribed with widely different bursting kinetics. Science 332: 472-474.

Sworder BJ, Yoshizawa S, Mishra PJ, Cherman N, Kuznetsov SA, Merlino G, Balakumaran A, Robey PG (2015) Molecular profile of clonal strains of human skeletal stem/progenitor cells with different potencies. Stem Cell Res 14: 297-306.

Tyagi S, Kramer FR (1996) Molecular beacons: probes that fluoresce upon hybridization. Nat Biotechnol 14: 303-308.

Wang J, Liao L, Wang S, Tan J (2013) Cell therapy with autologous mesenchymal stem cells-how the disease process impacts clinical considerations. Cytotherapy 15: 893-904.

Whitfield MJ, Lee WCJ, Van Vliet KJ (2013) Onset of heterogeneity in culture-expanded bone marrow stromal cells. Stem Cell Res 11: 1365-1377.

Yang C, Tibbitt MW, Basta L, Anseth KS (2014) Mechanical memory and dosing influence stem cell fate. Nat Mater 13: 645-652.

Yang R, Chen M, Lee CH, Yoon R, Lal S, Mao JJ (2010) Clones of ectopic stem cells in the regeneration of muscle defects in vivo. PLoS One 5: e13547.

Ylöstalo J, Bazhanov N, Prockop DJ (2008) Reversible commitment to differentiation by human multipotent stromal cells in single-cell-derived colonies. Exp Hematol 36: 1390-1402.

Zuk PA, Zhu M, Mizuno H, Huang J, Futrell JW, Katz AJ, Benhaim P, Lorenz HP, Hedrick MH (2001) Multilineage cells from human adipose tissue: implications for cell-based therapies. Tissue Eng 7: 211-228.

\section{Web References}

1. http://www.celltherapysociety.org/?page $=$ MSCCommittee

Editor's notes: There were no questions to the authors from reviewers of this paper. Therefore, there is no Discussion with Reviewers section.

The scientific editor for this paper was Martin Stoddart. 